\title{
Uso activo de recursos audiovisuales en la educación infantil
}

\section{Marta María Alvarez}

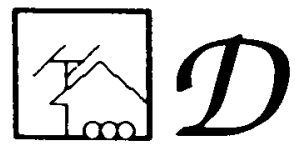

El uso activo de los medios audiovisuales en la escuela no sólo implica el aprendizaje de un nuevo código, sino que es un arma poderosa para crear interés y conciencia en los alumnos. En este artículo se exploran esas posibilidades en el marco del Diseño Curricular Base.

\section{INTRODUCCION}

Freinet, en «Parábolas para una pedagogía popular, «nos recomienda que, en el siglo de la imagen, ayudemos a los niños a superar etapas en las que la obra de arte era reducida a la clandestinidad.

La organización de los Centros de Interés en el aula de Educación Infantil, pretende abrir las puertas y ventanas del centro escolar aproximándonos al mundo que nos rodea.

En el mismo libro señalado anteriormente el autor indica:

«Si no os volvéis como niños, no entraréis en el reino encantado de la pedagogía... Lejos de tratar de olvidar vuestra infancia entrenaos en revivirla....

No es tarea sencilla revivir nuestra infancia, pero seguro que en ella encontraremos muchos recuerdos de fantasías, que con mayor o menor consciencia se mezclaban con la realidad. Seguro que también nos aproximamos a interpretaciones curiosas de nuestras vivencias.

Se trata de tomar un punto de vista a la altura de los ojos del niño, teniendo en cuenta que los ojos de nuestros niños están recibiendo mucha información por medio de imágenes audiovisuales.

Teniendo esto en cuenta, en la utilización de los Recursos Audio Visuales no nos limitaremos a la transmisión de conocimientos. Se tratará también de ayudar a los niños a «dominar» ese medio de expresión adoptando una actitud activa, y, en la medida de las posibilidades, crítica, frente a su poder de fascinación. 
El uso que se da a los RAV los incluye en el aula como un elemento manipulable. Será más que un visionado o una audición.

Permitirán:

Globalizar en torno a ellos

Que aparezcan en cualquier globalización.

\section{USO DIDACTICO DE LOS MEDIOS AUDIOVISUALES; OBJETIVOS EN LA EDUCACION INFANTIL}

El objetivo general puede ser: Emplear los medios audiovisuales no limitándonos a transmitir conocimientos, entretener y formar el gusto. Ayudar al niño a dominar esos medios adoptando una actitud activa y crítica frente a su poder de fascinación.

El vídeo además nos será útil para realizar evaluaciones, observando a los niños y estableciendo procesos de retroalimentación. También para valorar nuestra propia práctica, usándolo como elemento de triangulación.

El poder de la imagen del televisor resulta también atrayente para los padres, generalmente se muestran interesados en asistir a reuniones en las que se va a visionar y comentar un vídeo grabado en el aula. Se usa por tanto como recurso para incitar a la participación de los padres.

Usaremos los RAV para: informar, motivar, estimular la imaginación y la creatividad, evaluar e investigar, estudiar el propio medio audiovisual.

Dentro del marco curricular del DCB se hace referencia a los medios de comunicación. En este proyecto se han organizado dentro de las tres areas básicas.

Tal y como se indica en el DCB no se trata de un temario, ni son unidades compartimentadas que tengan sentido en sí mismas. Son simplemente cuestiones a tener en cuenta cuando se elaboran las programaciones.

\section{LA GLOBALIZACION}

En el esquema Figura 1 se pone de manifiesto la necesidad de que los contenidos y todo el proceso de enseñanza aprendizaje se interrelacione de forma global.

La globalización es más una cuestión de actitud que de técnica educativa. Supone introducir contenidos únicamente en el contexto de las experiencias del alumno.

El trabajo a realizar no está ligado a una necesidad de aprendizaje «per se», sino que es necesario para dar respuesta a las propias necesidades y demandas del niño.

No se trata de que «HOY TOCA RAV» y vamos a ver una bonita película. Los medios audiovisuales se integran dentro de la programación, del centro de interés o del pequeño proyecto, formando parte de todo el entramado.

Se trata de acabar con el uso de los RAV cimo tiempo de relleno, que quedó vacío de información y de contenido. Fin también al uso como premio a una conducta pasiva de los alumnos que gratificamos con otro tipo de pasividad y donde el poder de manipulación reside en la imagen proyectada. 
Fgura 1

Globalización

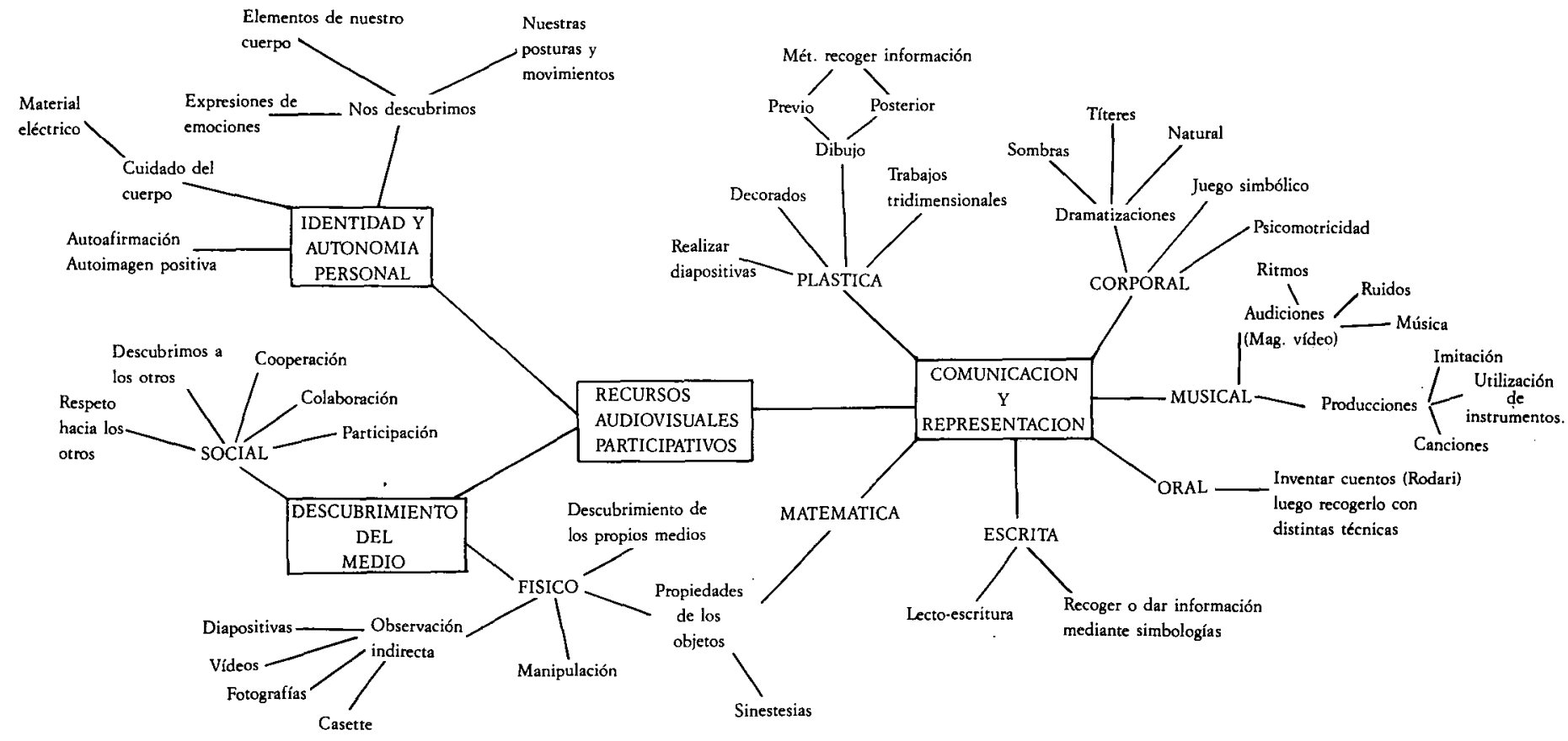


Figura 1 (Cont.)

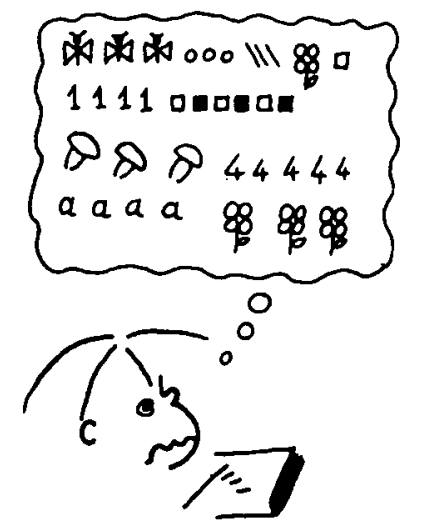

AHORA CERRAD TODOS VUESTRO HERMOSO CUADERNITO Y HAREMOS IANIMACLON! MASCARAS, CUENTOS, DANZA, TITERES, CANCONES, RITMO, TEATRO, PINTURA... IANIMO. VENGA OLE...
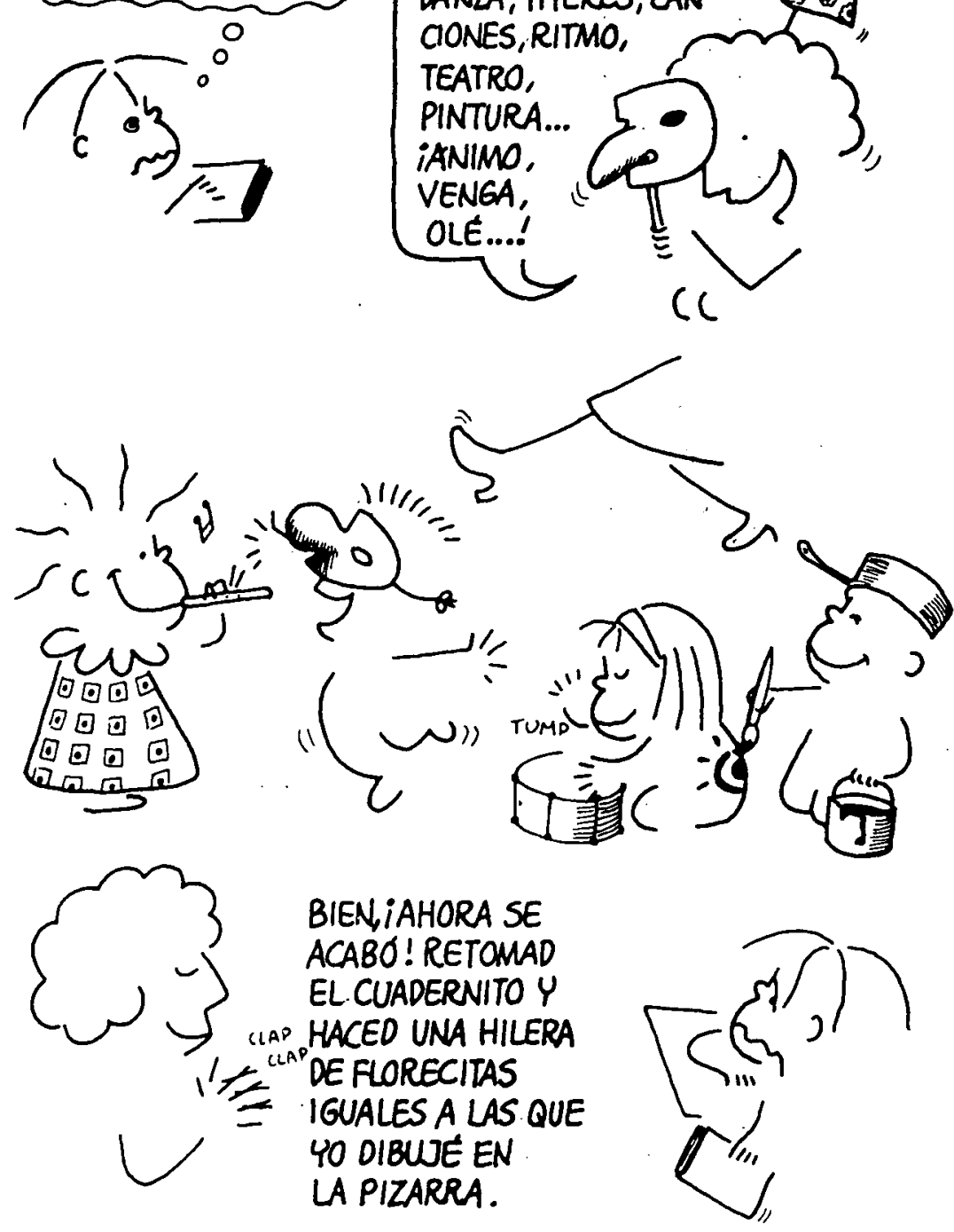

(1979) ¿Animación o reanimación? 
Tabla I

Area: Identidad y autonomia personal

\begin{tabular}{|c|c|c|c|}
\hline Objetivos & \multicolumn{3}{|c|}{ Contenidos } \\
\hline \multirow[b]{2}{*}{$\begin{array}{l}\text { - Descubrir su propia imagen, recogida me. } \\
\text { diante diferentes medios audiovisuales. } \\
\text { - Consolidar una imagen positiva de sí mismo. } \\
\text { - Descubrir y utilizar las posibilidades mo- } \\
\text { trices, sensitivas y expresivas del propio } \\
\text { cuerpo. } \\
\text { - Progresar en la adquisición de hábitos re- } \\
\text { lacionados con la seguridad personal. } \\
\text { - Adecuar su propio comportamiento a las ne- } \\
\text { cesidades, demandas, requerimientos y ex- } \\
\text { plicaciones de otros niños o adultos. }\end{array}$} & Hechos y conceptos & Procedimientos & Actitudes/Valores/Normas \\
\hline & $\begin{array}{l}\text {-El cuerpo humano. } \\
\text {-Sentimientos y emociones. } \\
\text { - Movimientos, posturas y gestos. } \\
\text { - Normas de convivencia. } \\
\text { - Sensaciones y percepciones. } \\
\text { - Cuidado de uno mismo. }\end{array}$ & $\begin{array}{l}\text { - Percepción de diferencias físicas. } \\
\text { - Configuración de la imagen } \\
\text { personal. } \\
\text { - Percepción y reconocimiento del } \\
\text { propio cuerpo. } \\
\text { - Manifestación y regulación de sen- } \\
\text { timientos. } \\
\text { - Utilización de los sentidos. } \\
\text { - Control progresivo del movimiento. } \\
\text { - Coondinación, cooperación, colabo- } \\
\text { ración. } \\
\text {-Utilización adecuada de instrumen- } \\
\text { tos para prevenir accidentes. }\end{array}$ & $\begin{array}{l}\text {-Aceptación de su propia identidad. } \\
\text { - Iniciativa para la realización de mo- } \\
\text { vimientos, interés por su precisión. } \\
\text { - Autonomía } \\
\text { - Actitudes de colaboración y soli- } \\
\text { daridad. } \\
\text { - Valoración positiva de las medidas } \\
\text { de seguridad. }\end{array}$ \\
\hline
\end{tabular}

TABLA II

Area: Descubrimiento del medio físico y social

\begin{tabular}{|c|c|c|c|}
\hline Objetivos & \multicolumn{3}{|c|}{ Contenidos } \\
\hline \multirow[b]{2}{*}{$\begin{array}{l}\text {-Reconocer los medios audiovisuales como } \\
\text { sistema de transmisión de información y } \\
\text { también de ocio. } \\
\text { - Utilizar los medios audiovisuales como sis- } \\
\text { tema de observación indirecta. } \\
\text { - Ofrecer oportunidades suficientes para que } \\
\text { el niño satisfaga su necesidad, su curiosi- } \\
\text { dad para aprender y descubrir, convirtien- } \\
\text { do el aula en un enfoque adecuado para la } \\
\text { formulación de preguntas, la exploración, } \\
\text { el contraste de opiniones. }\end{array}$} & Hechos y conceptos & Procedimientos & Actitudes/Valores/Normas \\
\hline & $\begin{array}{l}\text { - Los medios de comunicación su pa- } \\
\text { pel como instrumento para el ocio } \\
\text { y como difusores de acontecimien- } \\
\text { tos sociales. } \\
\text { - La observación indirecta. } \\
\text { - Distintos medios de comunicación. }\end{array}$ & $\begin{array}{l}\text { - Captación de información. } \\
\text { - Descubrimiento de aspectos de la } \\
\text { realidad poco accesibles mediante } \\
\text { observación directa. } \\
\text { - Construcción de aparatos, en fun- } \\
\text { ción de sus propios intereses. }\end{array}$ & $\begin{array}{l}\text { - Valoración acrítica» de la informa- } \\
\text { ción recibida. } \\
\text { - Curiosidad ante la exploración so- } \\
\text { bre los medios audiovisuales. } \\
\text { - Prudencia ante los factores de } \\
\text { riesgo. }\end{array}$ \\
\hline
\end{tabular}

TABLA III

Area: Comunicación y representación

\begin{tabular}{|c|c|c|c|}
\hline Objetivos & \multicolumn{3}{|c|}{ Contenidos } \\
\hline \multirow[b]{2}{*}{$\begin{array}{l}\text { - Leer, interpretar y producir imágenes como } \\
\text { una forma de comunicación y disfrute, des. } \\
\text { cubriendo e identificando los elementos bá. } \\
\text { sicos de su lenguaje. } \\
\text { - Utilizar las diversas formas de representa- } \\
\text { ción (lenguaje oral, escrito, expresión plás- } \\
\text { tica, dramática, corporal y musical, lenguaje } \\
\text { matemático) para evocar situaciones, accio- } \\
\text { nes, deseos y sentimiento sean de tipo real } \\
\text { o imaginario. } \\
\text {-Utilizar las técnicas más básicas (pintura, } \\
\text { modelado, canto, dramatización) para } \\
\text { aumentar sus posibilidades expresivas. }\end{array}$} & Hechos y conceptos & Procedimientos & Actitudes/Valores/Normas \\
\hline & $\begin{array}{l}\text {-Diferencias entre lengua escrita, di- } \\
\text { bujo, y fotografía. } \\
\text { - Diversidad de obras plásticas que es } \\
\text { posible producir y que se encuen- } \\
\text { tran presentes en el entorno: pintu. } \\
\text { ra, escultura, programas de TV } \\
\text { películas, fotografías, dibujo, ilustra- } \\
\text { ciones diversas. } \\
\text { - Ruido, silencio, música, canción. } \\
\text { - Las propiedades sonoras del cuer- } \\
\text { po, de los objetos cotidianos, de ins- } \\
\text { trumentos musicales. }\end{array}$ & $\begin{array}{l}\text {-Interpretación de imágenes, carte- } \\
\text { les, grabados, fotografías que acom- } \\
\text { pañan a textos escritos, estable- } \\
\text { ciendo relación entre ambos. } \\
\text { - Producción y utilización de imáge- } \\
\text { nes debidamente secuenciadas. } \\
\text { - Producción y utilización de sistemas } \\
\text { de simbolos. Para transmitir men- } \\
\text { sajes simples. } \\
\text { - Interpretación de diferentes tipos de } \\
\text { imágenes presentes en su entorno. } \\
\text {-Imitación de sonidos y exploración } \\
\text { de propiedades sonoras de mate- } \\
\text { riales. }\end{array}$ & $\begin{array}{l}\text { - Valorar positivamente todas las for- } \\
\text { mas de expresión. } \\
\text { - Gusto por utilizar la imagen en to- } \\
\text { dos sus ámbitos, exploríndola. } \\
\text { - Disfrute con la experimentación, } \\
\text { participando y produciendo. }\end{array}$ \\
\hline
\end{tabular}




\section{ACTIVIDADES}

En la organización globalizada de los RAV se proponen diferentes clases de actividades:

\section{En el aula}

1. Dentro del planteamiento de un centro de interés surge la utilización de un recurso audiovisual.

Ejemplo: En la clase ha surgido el Centro de Interés «el agua». La manipulamos, jugamos, vemos que se ensucia y queremos tocar el tema de la contaminación. Todos (niños y profesora) buscamos documentación; libros, fotografías, diapositivas y un vídeo sobre el tema nos permiten observar, comentar y trabajar sobre todas las áreas que plantea el DCB.

2. Un recurso audiovisual introduce un centro de interés.

Ejemplo: A partir de una grabación magnetofónica, que nos deja un personaje fantástico, que se hace real en nuestra clase, nos interesamos por un determinado centro de interés.

Ejemplo: Un cuento que nos llega a través de un medio audiovisual, como el vídeo, nos interesa más y nos proporciona más información.

\section{Aproximación a los padres}

El vídeo, fundamentalmente las grabaciones realizadas en el aula, resulta siempre muy interesante para los padres. Es sin lugar a dudas, un buen sistema para que comprendan la tarea que se realiza en el aula y para invitarlos a participar en ella.

\section{Evaluación}

Resulta el vídeo un buen instrumento, facilitador de la observación de nuestra propia práctica y de los efectos que produce en los niños.

\section{OTROS FACTORES METODOLOGICOS}

Trataremos de conseguir aprendizajes significativos, para ello tendremos en cuenta las condiciones planteadas por COLL:

- Conseguir una actitud favorable a la realización de los aprendizajes.

- Es decir, actuar sobre los intereses de los niños, no es tarea excesivamente difícil aunque pudiera parecerlo a priori. Fundamentalmente se trata de poner nuestros ojos a la altura de los niños y estar atentos a la información que ellos nos proporcionan.

- Buscar la coberencia interna del material, es decir no considerar la utilización de los medios audiovisuales como algo independiente del programa, que se adjunta cuando hace mal tiempo o cuando el profesor encuentra un «buen» vídeo.

- Actuar dentro del area de desarrollo próximo de cada niño aportando información y experiencias próximas a la situación de aprendizaje en que se encuentran los niños. 
Pretenderemos también una metodología abierta, lo programado se irá ajustando a la realidad concreta del momento y a la dinámica particular del curso.

Activa, pero que no caiga en el error del hacer por hacer. Se trata de que los niños manipulen, observen, experimenten y lleguen a conclusiones. Es decir, trataremos más que de enseñar de dejar aprender. De proporcionar estrategias y experiencias.

Socializadora, que permita el trabajo en equipo y la interacción con los iguales y con el profesor. Pero siempre teniendo en cuenta las necesidades individuales y proporcionando posibilidades de juego en el trabajo individual.

Integral, considerando al niño como un todo que debe crecer y desarrollarse de forma equilibrada y armónica.

Buscaremos por tanto un clima ameno eñ el que el niño pueda experimentar, comunicar, desarrollarse y progresar siendo feliz.

\section{RECURSOS}

\section{Materiales}

La variedad de instrumentos que favorecen que los niños conozcan diversas técnicas y puedan ser críticos con ellas es útil fundamentalmente si ellos pueden intervenir sobre esos recursos: radiocasete, televisor y magnetoscopio, cámara de vídeo, retroproyector, proyector de diapositivas...

\section{Espaciales}

Como en cualquier planificación, se considera básico utilizar la mayor variedad de espacios del colegio, así como explorar entornos próximos.

Sería útil tratar de recordar algún espacio «Mágico» de nuestra infancia; el colegio puede tener también algún rincón especial, tal vez mágico, y relacionado o relacionable con el uso de Recursos Audio Visuales.

\section{Referencias}

Col C. y Solé I. (1989): «Aprendizaje significativo y ayuda pedagógica» Cuadernos de pedagogía n. 168 pp. $16-20$.

Coll C. Y OTROS (1986): Evaluación y seguimiento en parvulario y ciclo inicial. Ed. Visor. Madrid. M.E.C. (1989): Diseño Curricular Base. Centro de publicaciones del MEC Madrid. Tonnucci, F. (1987): Con ojos de niño. Ed. Barcanova Educación. Barcelona.

$\mathrm{Z}_{\mathrm{ABALA}}$, A. (1989): «El enfoque globalizador» Cuademos de pedagogía n. ${ }^{\circ} 168$, pp. 22-27.

Freinet C. (1979): Parábolas para una pedagogía popular. Ed. Laia. Barcelona. 


\section{Uso activo de recursos audiovisuales en la} educación infantil. Marta María Alvarez. CL\&E, 1992, 14, pp. $49-56$

Resumen: Cotidianamente estamos recibiendo variada información audiovisual que nos resulta fascinante y capta con facilidad nuestra atención. La evidencia de esa influencia sobre los niños nos impulsa a utilizar los recursos audiovisuales en las aulas y en los colegios tratando de desarrollar el sentido crítico y la imaginación.

La propuesta que aquí se hace sobre la utilización de los RAV en Educación Infantil propone una metodología global, significativa y activa, pero no activista.

Datos sobre la autora: Marta María Alvarez trabaja en Educación Infantil procurando situarse en el punto de vista de los niños y permeabilizando el aula a la realidad que vivimos fuera. Un recurso fundamental en esta tarea son los medios audiovisuales. Sobre su utilización en su práctica ha impartido alguna ponencia durante 1990-1991. Es profesora en el Colegio Público de San Pedro de los Arcos. Oviedo.

Dirección: Julián Cañedo, 7, 9. $\mathrm{C}$. Oviedo.

(C) De todos los artículos deberá solicitarse por escrito autorización de CL\&E y de los autores para el uso en forma de facsímil, fotocopia o cualquier otro medio de reproducción impresa. CL\&E se reserva el derecho de interponer las acciones legales necesarias en aquellos casos en que se contravenga la ley de derechos de autor. 